\title{
Serum NGAL, KIM-1, IL-18, L-FABP: new biomarkers in the diagnostics of acute kidney injury (AKI) following invasive cardiology procedures
}

\author{
Magdalena Zdziechowska ${ }^{1}$ Anna Gluba-Brzózka ${ }^{1}$ ( $)$ Adam R. Poliwczak ${ }^{2} \cdot$ Beata Franczyk $^{1} \cdot$ Michał Kidawa $^{3}$. \\ Marzenna Zielinska ${ }^{3}$. Jacek Rysz ${ }^{1}$
}

Received: 7 November 2019 / Accepted: 1 June 2020 / Published online: 17 June 2020

(c) The Author(s) 2020

\begin{abstract}
Purpose The aim of this study was to assess the levels of selected markers in patients who underwent planned or emergency coronary angiography and to examine if they correlated with the occurrence of AKI.

Methods The study included 52 patients who underwent planned or emergency coronary angiography and received contrast agent. Serum levels of markers (NGAL, L-FABP, KIM-1, IL-18) were analyzed in all patients using ELISA tests, at baseline, after 24 and $72 \mathrm{~h}$ from angiography.

Results $9.62 \%$ of patients developed CI-AKI. No significant differences were observed between markers levels in patients who developed CI-AKI and those who did not. After $24 \mathrm{~h}$, serum levels of IL-18 were higher in patients with CI-AKI, however, this difference was on the verge of significance. Increase in serum NGAL, KIM-1 and IL-18 was observed after $24 \mathrm{~h}$. Serum levels of biomarkers were insignificantly higher in group with CI-AKI. Significant changes in levels in time (baseline vs. $24 \mathrm{~h}$ vs. $72 \mathrm{~h}$ ) were observed only for NGAL [157.9 (92.4-221.0) vs. 201.8 (156.5-299.9) vs. 118.5 (73.4-198.7); $p<0.0001]$. No significant correlations were observed between the decrease in eGFR or the increase in creatinine and biomarkers level.

Conclusion Obtained results do not allow for the indication of efficient AKI biomarkers. Their further validation in large studies of CI-AKI patients is required.
\end{abstract}

Keywords NGAL $\cdot$ L-FABP $\cdot$ KIM-1 $\cdot$ IL-18 $\cdot$ Acute kidney injury $\cdot$ Contrast-induced $\cdot$ Biomarkers

\section{Introduction}

Acute kidney damage is a clinical syndrome that develops as a result of sudden impairment of kidney function [1]. It is characterized by a wide spectrum of disorders ranging from a temporary increase in the concentration of biological markers, impaired renal function (elevated creatinine levels, decrease in GFR) to severe metabolic and clinical disorders,

Anna Gluba-Brzózka

aniagluba@yahoo.pl

1 Department of Nephrology, Hypertension and Family Medicine, Medical University of Lodz, Zeromskiego 113, 90-549 Lodz, Poland

2 Department of Human Physiology, Chair of Experimental and Clinical Physiology, Medical University of Lodz, Lodz, Poland

3 Department of Intensive Cardiac Therapy, Central Teaching Hospital of the Medical University of Lodz, Lodz, Poland or even the necessity to undergo renal replacement therapy. Acute kidney injury occurring shortly after the intravenous injection of iodinated contrast material (CM) includes: postcontrast AKI which may or may not be directly caused by the contrast material and contrast-induced AKI (CI-AKI), previously called "contrast-induced nephropathy" (CIN), which can be causally linked to contrast material administration. CI-AKI has been observed after the use of radiocontrast media for coronary angiography (CAG) with or without percutaneous coronary intervention (PCI) [2]. The reported incidence of CIN in high-risk patients following CAG varies from 10 to $20 \%$ [3]. CI-AKI risk in post-PCI patients could be related either to the patient (advanced age, concomitant diseases, dehydration, and concomitant use of other nephrotoxic drugs) or procedure related (intra-arterial route of administration, the use of high osmolar CM, repeated exposure to contrast within $48 \mathrm{~h}$, volume of contrast used, etc.) [4]. Among risk factors for the development of acute kidney damage there are: age $>70$ years, diabetes 
mellitus, chronic kidney disease, circulatory failure, atrial fibrillation, gout, infections, surgery, some drugs (NSAIDs, diuretics, aminoglycosides and vancomycin) [5]. The prevalence of CI-AKI in persons with normal renal function is low $(0-5 \%)$, but it increases along with the deterioration of kidney function-in patients with moderate impairment of renal function (GFR $45-60 \mathrm{ml} / \mathrm{min}$ ) it reaches about $10-30 \%$, in patients with severe renal impairment (GFR $<45 \mathrm{ml} / \mathrm{min}$ ) it is less than $50 \%$, while in diabetic nephropathy it exceeds $50 \%$ [6]. Some former studies reported high risk of CI-AKI in general population, however, according to more recent studies its incidence is about $0.8-1.7 \%$. The discrepancies in the incidence of CI-AKI in many studies may be partly explained by the fact that small rises of serum creatinine are quite common in sick patients, even in those not receiving contrast $[7,8]$ and also by the current use of lower doses of contrast, improved technologies as well as risk stratification of patients which enables the avoidance of contrast administration in the most risky patients. Contrast-induced nephropathy involves acute kidney damage with acute tubular necrosis sometimes leading to end-stage renal disease [9]. The Kidney Disease Improving Global Outcomes (KDIGO) working group suggests that AKI should be diagnosed when serum creatinine level has increased by at least $0.3 \mathrm{mg} / \mathrm{dl}$ ( $26.5 \mu \mathrm{mol} / \mathrm{l})$ over the baseline value within $48 \mathrm{~h}$ after the exposure to contrast medium, or it has increased 1.5 times or more over the baseline value within 7 days after the exposure to contrast medium, or a urinary volume of less than $0.5 \mathrm{ml} /$ $\mathrm{kg} / \mathrm{h}$ that persists for at least $6 \mathrm{~h}$ after exposure is observed [10]. Moreover, other causes for AKI such as atheroemboli, among others should be excluded [7].

Acute kidney damage increases patients' morbidity and mortality, prolongs hospitalization and enhances the risk of chronic kidney disease and cardiovascular events [6]. Due to the seriousness of CI-AKI prognosis, it should be recognized as soon as possible, effectively treated, and preferably prevented. The monitoring of renal function on the basis of creatinine and GFR in the assessment of contrast-induced nephropathy, is not always sufficient. Apart from the determining of serum creatinine (which is a late marker of kidney function, not its damage), new biomarkers of acute kidney damage are helpful in the diagnosis. Neutrophil gelatinaseassociated lipocalin (NGAL), kidney injury molecule-1 (KIM-1), interleukin-18 (IL-18) and liver fatty acid-binding protein (L-FABP) have been suggested to be early markers of acute kidney injury, which effectiveness should be confirmed in studies $[3,4,11]$. NGAL is a glycoprotein produced by neutrophils and epithelial cells of various organs [12]. This protein is released from the proximal nephron tubule cells into the bloodstream following ischemia and nephrotoxic damage [13]. NGAL seems to be a good early marker in the diagnosis of acute kidney damage in patients undergoing PCI because the increase in its concentration occurs significantly earlier than changes in creatinine levels [14]. The peak of NGAL level in serum was observed $2 \mathrm{~h}$ after PCI [15].

KIM-1 is a type 1 transmembrane protein which expression is significantly increased in the proximal tubule in the ischemic kidney $[16,17]$. KIM-1 is a promising factor in the diagnosis of acute kidney damage with a predictive value in patients undergoing cardiac surgery. This is the first biomarker that specifically reflects proximal renal tubular damage $[16,17]$.

IL-18-is a pro-inflammatory cytokine which activity increases in the course of inflammatory processes. It is a mediator of tissue damage caused by hypoxia [18]. Urine IL-18 is an early, fast and inexpensive marker allowing the detection of early kidney damage caused by ischemia or nephrotoxins [4]. However, a little is known about the potential of serum IL-18 as AKI biomarker.

L-FABP-liver fatty acid binding protein-is a newly discovered biomarker for early diagnosis of acute conditions [19]. In acute renal damage caused by contrast agents during PCI, a significant increase in L-FABP excretion has been demonstrated after 1, 2 and $14 \mathrm{~h}$ from the procedure in patients who developed contrast nephropathy [20].

The aim of this study was to assess the levels of selected markers in patients who underwent planned or emergency coronary angiography and to correlate it with possible occurrence of CI-AKI.

\section{Materials and methods}

This study included 52 patients from the Med Pro Cardiological Center of Zgierz and from the Department of Intensive Cardiac Therapy, Central Teaching Hospital of the Medical University of Lodz, who underwent planned or emergency coronary angiography and received contrast agent. The study was approved by the Bioethics Committee of the Medical University of Lodz (No. RNN/26/18/KE of 16.01.2017) and conducted according to the principles expressed in the Declaration of Helsinki. All subjects enrolled in this study were informed about its purpose and methodology and signed an informed consent form. Exclusion criteria were as follows: state after kidney transplantation, haemoglobin $<8 \mathrm{~g} /$ $\mathrm{dl}$, active cancer, active hepatitis B or C, mental disease, alcoholism, HIV infection or other immune disorders and lack of consent to participate in the study. A complete medical history was obtained from all participants. The levels of selected markers were analyzed in blood of all patients involved in the study. In the present study, serum levels of selected biomarkers of proteins: KIM-1 (Cloud-Clone Corp, no. SEA785Hu), IL-18 (BioVendor, No. RAF143R), Lipocalin-2/NGAL (BioVendor, No. RD191102200R), L-FABP (MyBioSource, No. MBS017865) were determined using 
ELISA method according to the manufacturer's instructions. Serum creatinine, NGAL, KIM-1, IL-18, L-FABP were measured at baseline and after 24 and $72 \mathrm{~h}$ after angiography. Additional measures for preventing CI-AKI were individualized according to the recommendations of attending physician. Estimated glomerular filtration rate (eGFR) was calculated using simplified 4-variable Modification of Diet in Renal Disease (MDRD) formula:

e GFR $=186 \times($ s erum $\quad$ creat i nine $)^{-1.154} \times(\text { age })^{-0.203} \times[0.742$ if female] [21].

Contrast-induced AKI (CI-AKI) has been diagnosed in patients in whom a $25 \%$ creatinine rise within $48 \mathrm{~h}$ was observed [22]. Heart failure was diagnosed based upon available medical history, or typical signs and symptoms as well as on objective evidence of structural or functional abnormality of the heart (ESC HF Guidelines 2016) [23].

\section{Statistical analysis}

Data were presented as percentages or as median with interquartile range (median 25-75\%) to account for the skewed nature of parameters given the small sample size. The Shapiro-Wilk test was used to verify normal distribution of variables and Levene test to analyze the homogeneity of variance. The $\chi^{2}$ test of independence was used for the analysis of discontinuous variables. Standard Student $t$ test was utilized for the comparison of data showing no departures from normality, and the non-parametric Mann-Whitney $U$ test for the remaining variables. Friedman nonparametric test was used to compare levels of selected markers in different time points. Significance level $p<0.05$ was considered as statistically significant. Statistical analyses were performed using GraphPad Prism7, GraphPad Software, San Diego, CA, USA.

\section{Results}

Table 1 presents baseline characteristics of all patients enrolled into this study.

Of the 52 recruited patients, 5 (9.6\%) developed CI-AKI. Patients who developed CI-AKI were more likely to be older, to have STEMI or NSTEMI and higher GFR. Table 2 presents the comparison of characteristics of patients who developed CI-AKI and who did not.

Table 3 summarizes median levels of NGAL $(\mathrm{ng} / \mathrm{mL})$, L-FABP (ng/mL), IL-18 and F-FABP in patients who developed CI-AKI and those who did not.

No significant differences were observed between selected markers levels in patients who developed CI-AKI and those who did not. After $24 \mathrm{~h}$, only serum levels of IL-18 were much higher in patients with CI-AKI than in
Table 1 Baseline characteristics of patients

\begin{tabular}{ll}
\hline Total sample $n=52$ & \\
\hline Age (years) & $66.4 \pm 8.7$ \\
Male $n(\%)$ & $31(60 \%)$ \\
BMI & $29.2 \pm 4.1$ \\
Hypertension $n(\%)$ & $45(87 \%)$ \\
Diabetes mellitus $n(\%)$ & $15(29 \%)$ \\
Heart failure & $26(50 \%)$ \\
Atrial fibrillation & $9(17 \%)$ \\
Hypercholesterolemia $n(\%)$ & $22(42 \%)$ \\
Planned coronary angiography $n(\%)$ & $12(23 \%)$ \\
Emergency coronary angiography $n(\%)$ & $40(77 \%)$ \\
Indication for PCI at index admission $n(\%)$ & \\
STEMI & $1(2 \%)$ \\
NSTEMI & $9(17 \%)$ \\
UA & $35(67 \%)$ \\
Arterial stenosis $n(\%)$ & $19(37 \%)$ \\
Serum creatinine at admission $(\mu \mathrm{mol} / \mathrm{L})$ & $81.0 \pm 20.0$ \\
Mean eGFR at admission $\left(\mathrm{mL} / \mathrm{min} / 1.73 \mathrm{~m}^{2}\right)$ & $83.4 \pm 20.7$ \\
eGFR at admission $<60 \mathrm{~mL} / \mathrm{min} / 1.73 \mathrm{~m}{ }^{2}$ & $7(13 \%)$ \\
Mean contrast-medium volume & $111.7 \pm 88.7$ \\
Serum NGAL at admission $(\mathrm{ng} / \mathrm{mL})$ & $201.8(156.5-299.9)$ \\
Serum KIM-1 at admission $(\mathrm{ng} / \mathrm{mL})$ & $130.2(42.4-341.9)$ \\
Serum IL-18 at admission $(\mathrm{ng} / \mathrm{mL})$ & $261.6(241.7-365.7)$ \\
Serum L-FABP at admission $(\mathrm{ng} / \mathrm{mL})$ & $4.7(2.7-5.0)$ \\
\hline
\end{tabular}

STEMI ST elevation myocardial infarction, NSTEMI non-ST-elevation myocardial infarction, $U A$ unstable angina

those without acute kidney injury, however, this difference was on the verge of significance. In case of NGAL, KIM-1 and IL-18, an increase in their serum levels can be observed after $24 \mathrm{~h}$ in CI-AKI group, while after $72 \mathrm{~h}$, a decrease in serum concentration of these three markers can be seen. In turn, constant increase in L-FABP can be observed even after $72 \mathrm{~h}$ in this group. In patients without CI-AKI, an increase in NGAL and KIM-1 levels was found after $24 \mathrm{~h}$ and a decrease after $72 \mathrm{~h}$. L-FABP and IL-18 levels seemed to be rather stable in this group in all time points. Despite a lack of statistical significance, it can be observed that serum levels of analyzed biomarkers were higher in the group of patients who developed CI-AKI.

Table 4 presents changes in studied biomarkers serum levels in all patients enrolled into this study.

The statistically significant changes in biomarkers serum levels in time were observed only in the case of NGAL (Table 5).

No significant correlations were observed between the decrease in eGFR level and increase in creatinine level after $24 \mathrm{~h}$ and $72 \mathrm{~h}$ days from the procedure and the levels of selected biomarkers (Table 6). 
Table 2 Baseline characteristics of patients who developed CI-AKI and those who did not
Table 3 Comparison of selected markers levels in patients who developed CI-AKI and those who did not

\begin{tabular}{llll}
\hline Demographic & $\begin{array}{l}\text { Group of patients } \\
\text { who developed CI- } \\
\text { AKI } \\
(n=5)\end{array}$ & $\begin{array}{l}\text { Group of patients who } \\
\text { did not develop CI-AKI } \\
(n=47)\end{array}$ & $p$ value \\
& $4(80 \%)$ & $27(57 \%)$ & 0.33 \\
\hline Male $(n, \%)$ & $67.1 \pm 8.8$ & $60 \pm 4.3$ & $\mathbf{0 . 0 5}$ \\
Age (years) & $29.3 \pm 2.2$ & $29.1 \pm 4.3$ & 0.94 \\
BMI & $5(100 \%)$ & $40(85 \%)$ & 0.81 \\
Hypertension $(n, \%)$ & $1(20 \%)$ & $21(45 \%)$ & 0.56 \\
Hypercholesterolemia $(n, \%)$ & $3(60 \%)$ & $12(26 \%)$ & 0.27 \\
DM $(n, \%)$ & $2(40 \%)$ & $7(15 \%)$ & 0.43 \\
Atrial fibrillation $(n, \%)$ & $4(80 \%)$ & $22(47 \%)$ & 0.35 \\
Heart failure $(n, \%)$ & $1(20 \%)$ & $11(23 \%)$ & 0.69 \\
Planned coronary angiography $(n, \%)$ & $5(100 \%)$ & $35(74 \%)$ & 0.52 \\
Emergency coronary angiography $(\mathrm{n}, \%)$ & $3(60 \%)$ & $7(15 \%)$ & $\mathbf{0 . 0 1}$ \\
STEMI/NSTEMI $(n, \%)$ & $2(40 \%)$ & $33(70 \%)$ & 0.39 \\
UA $(n, \%)$ & $3(60 \%)$ & $16(34 \%)$ & 0.51 \\
Arterial stenosis $(n, \%)$ & $81.2 \pm 26.4$ & $80.9 \pm 19.3$ & 0.49 \\
Creatinine $(\mu \mathrm{mol} / \mathrm{L})$ & $80.6(53.6-109.3)$ & $77.1(67.8-90.2)$ & \\
Baseline GFR & $95.9 \pm 32.39$ & $82.0 \pm 18.5$ & $\mathbf{0 . 0 8}$ \\
eGFR at admission $<60$ mL/min/1.73 m ${ }^{2}(n \%)$ & $0(0 \%)$ & $83.9(73.4-93.4)$ & 0.97 \\
Contrast volume $(\mathrm{ml})$ & $140 \pm 79.3$ & $110.8 \pm 89.2$ & 0.49 \\
\hline
\end{tabular}

Bolded values indicate statistical significance

DM diabetes mellitus, CKD chronic kidney disease, STEMI ST elevation myocardial infarction, NSTEMI non-ST-elevation myocardial infarction, $U A$ unstable angina

\begin{tabular}{lclcc}
\hline Biomarker & Time $(\mathrm{h})$ & $\begin{array}{l}\text { Group of patients who } \\
\text { developed CI-AKI }\end{array}$ & $\begin{array}{l}\text { Group of patients who did } \\
\text { not develop CI-AKI }\end{array}$ & $p$ value \\
\hline NGAL (ng/mL) & 0 & $164.8(136.2-309.3)$ & $157.9(92.4-220.2)$ & 0.52 \\
& 24 & $213.6(85.0-362.5)$ & $208.0(157.8-299.9)$ & 0.44 \\
& 72 & $192.7(83.5-289.8)$ & $118.5(73.4-173.9)$ & 0.25 \\
KIM-1 (pg/mL) & 0 & $113.0(47.9-365.9)$ & $70.2(62.4-311.2)$ & 0.95 \\
& 24 & $232.6(98.1-503.9)$ & $103.7(42.4-341.9)$ & 0.07 \\
& 72 & $118.5(74.0-157.1)$ & $90.3(34.3-420.4)$ & 0.89 \\
L-FABP (ng/mL) & 0 & $3.7(1.8-5.3)$ & $4.7(2.9-5.0)$ & 0.98 \\
& 24 & $4.5(3.2-5.5)$ & $4.8(2.7-5.3)$ & 0.37 \\
IL-18 (pg/mL) & 72 & $5.0(3.7-5.4)$ & $4.6(3.0-5.4)$ & 0.79 \\
& 0 & $291.3(271.5-380.6)$ & $261.6(236.8-353.3)$ & 0.58 \\
& 24 & $340.9(326.0-427.7)$ & $264.1(219.4-350.8)$ & $\mathbf{0 . 0 5}$ \\
& 72 & $316.1(291.3-358.3)$ & $251.4(244.2-328.5)$ & 0.38 \\
\hline
\end{tabular}

Bolded value indicate statistical significance

\begin{tabular}{lcccc}
\hline & Time (baseline) & Time $(24 \mathrm{~h})$ & Time $(72 \mathrm{~h})$ & Significance \\
\hline NGAL $(\mathrm{ng} / \mathrm{mL})$ & $157.9(92.4-221.0)$ & $201.8^{* *}(156.5-299.9)$ & $* * * 118.5 \# \#(73.4-198.7)$ & $\boldsymbol{p}<0.0001$ \\
KIM-1 (pg/mL) & $96.0(47.9-366.0)$ & $130.2(42.4-341.9)$ & $102.2(35.0-299.1)$ & NS $(p=0.59)$ \\
IL-18 (pg/mL) & $261.6(241.7-365.7)$ & $281.4(226.9-350.8)$ & $280.4(246.7-340.9)$ NS $(p=0.86)$ \\
L-FABP $(\mathrm{ng} / \mathrm{mL})$ & $4.7(2.7-4.9)$ & $4.7(2.6-5.3)$ & $4.7(2.9-5.4)$ & NS $(p=0.49)$ \\
\hline
\end{tabular}

Friedman test

${ }^{* *} p<0.01 ; * * * p<0.0001$ vs baseline; ${ }^{\# \#} p<0.01$ vs time ( 1 day) 
Table 5 The analysis of relationship between selected markers and the decrease in eGFR level in all patients included in this study

\begin{tabular}{lclcc}
\hline & Time $(24 \mathrm{~h})$ & Significance & Time $(72 \mathrm{~h})$ & Significance \\
\hline NGAL $(\mathrm{ng} / \mathrm{mL})$ & $79.8(136.1-279.8)$ & 0.76 & $71.4(118.5-241.8)$ & 0.60 \\
KIM-1 $(\mathrm{pg} / \mathrm{mL})$ & $40.3(74.9-282.3)$ & 0.11 & $34.7(112.8-198.1)$ & 0.53 \\
IL-18 $(\mathrm{pg} / \mathrm{mL})$ & $215.7(291.3-358.3)$ & 0.96 & $234.3(269.0-316.1)$ & 0.42 \\
L-FABP $(\mathrm{ng} / \mathrm{mL})$ & $2.5(4.8-5.5)$ & 0.32 & $3.4(5.0-5.4)$ & 0.65 \\
\hline
\end{tabular}

\begin{tabular}{lclcl}
\hline & Time $(1$ day $)$ & Significance & Time (3 day) & Significance \\
\hline NGAL $(\mathrm{ng} / \mathrm{mL})$ & $80.0(136.2-272.9)$ & 0.79 & $72.0(122.5-227.1)$ & 0.58 \\
KIM-1 $(\mathrm{pg} / \mathrm{mL})$ & $40.4(70.2-252.1)$ & $\mathbf{0 . 0 6}$ & $34.8(96.8-195.6)$ & 0.38 \\
IL-18 $(\mathrm{pg} / \mathrm{mL})$ & $215.7(291.3-358.3)$ & 0.96 & $234.3(269.0-316.1)$ & 0.42 \\
L-FABP $(\mathrm{ng} / \mathrm{mL})$ & $2.5(4.7-5.5)$ & 0.98 & $2.8(4.8-5.4)$ & 0.98 \\
\hline
\end{tabular}

Table 6 The analysis of relationship between selected markers and the increase in creatinine level in all patients included in this study
$\mathrm{mL}(241.7-365.7 \mathrm{pg} / \mathrm{mL})$ and L-FABP-4.7 $\mathrm{ng} / \mathrm{mL}$ $(2.7-5.0 \mathrm{ng} / \mathrm{mL})$.

Of the 52 recruited patients, 5 (9.6\%) developed CI-AKI. According to literature, the strongest risk factor for CI-AKI development is the presence of pre-existing CKD [22]. In this study, patients who developed CI-AKI were more likely to be older, to have STEMI or NSTEMI and to show have higher GFR. The last observation may be surprising, but it could be associated with the fact that these patients received greater volume of contrast than patients who did not develop AKI $(140 \pm 79.3$ vs. $110.8 \pm 89.2)$. Moreover, all of them underwent emergency procedures, so it can be hypothesized that they were not provided with sufficient hydration before the surgery. Connolly et al. [22] demonstrated that in their study CI-AKI was considerably associated with increasing age, lower GFR, higher creatinine, higher volumes of contrast, anemia, diabetes and administration of intravenous fluids. Also in our study, the prevalence of diabetes in patients who developed CI-AKI was higher in comparison to patients without AKI (60\% vs. 26\%), however, the difference was not statistically significant.

In this study, we generally failed to find any significant differences between selected markers levels in patients who developed CI-AKI and those who did not. After 24 h, only serum levels of IL-18 were much higher in patients with CI-AKI than in those without acute kidney injury, however, this difference was on the verge of significance. In case of NGAL, KIM-1 and IL-18, an increase in their serum levels can be observed after $24 \mathrm{~h}$ in CI-AKI group, while after $72 \mathrm{~h}$ from the procedure a decrease in serum concentration of these three markers can be seen. In turn, constant increase in L-FABP was observed even after $72 \mathrm{~h}$ in CI-AKI group. In patients without CI-AKI, an increase in NGAL and KIM-1 levels was found after $24 \mathrm{~h}$ and a decrease after 72 h. L-FABP and IL-18 levels seemed to be rather stable in this group in all time points. Despite a lack of statistical significance, it can be observed that serum levels of 
analyzed biomarkers were higher in the group of patients who developed CI-AKI. According to available literature NGAL is released into plasma and urine after renal tubular cell damage, which results in an increase in its plasma and urine concentration. NGAL secretion occurs much earlier than the rise in serum concentration of creatinine $[14,26]$. Therefore, NGAL seems to have potential to become a great, independent predictor of AKI [14, 27, 28]. Numerous studies indicated that NGAL could be an early, sensitive and noninvasive biomarker for predicting CI-AKI in various cardiovascular conditions $[24,29,30]$. Similar increase within $24 \mathrm{~h}$ followed by a decline in NGAL concentration was observed by Padhy et al. [31]. They demonstrated that serum NGAL increased sharply at $4 \mathrm{~h}$ after the angiography and then it gradually diminished to the level that was near normal range at $48 \mathrm{~h}$ in AKI cases. In that study, the optimum cut-off of serum NGAL was found to be $155.2 \mathrm{ng} / \mathrm{mL}$ at $4 \mathrm{~h}$ and $89.5 \mathrm{ng} / \mathrm{mL}$ at $24 \mathrm{~h}$ from procedure [31]. Other studies have found NGAL elevation in patients who developed CI-AKI after 2-4 h post-angiography [22, 32-34]. In turn, according to Connolly et al. [22], the best predictive time-point for measurement of plasma NGAL ( $>964 \mathrm{ng} / \mathrm{dL}$ ) was the $6 \mathrm{~h}$. They suggested that negative result of plasma NGAL determination at $6 \mathrm{~h}$ meant that patients had low risk $(<4 \%)$ of developing CI-AKI and so they could be safely discharged from hospital care with appropriate CI-AKI advice. Also, the study conducted by Quintavalle et al. [34] demonstrated the use of serum and urine NGAL levels at $6 \mathrm{~h}$ might allow for the exclusion of CI-AKI development (serum NGAL sensitivity $74 \%$, specificity $52 \%$, AUC $0.62, p=0.045$ and urine NGAL sensitivity of $75 \%$, specificity $52 \%$, AUC 0.61 , $p=0.001$ ). A meta-analysis of 2538 patients revealed that AUC-ROC of NGAL for predicting AKI across all settings was 0.83 (95\% CI, 0.74-0.91) when a median cut-off value of $>150 \mathrm{ng} / \mathrm{mL}$ and common creatinine-based definition of AKI (defined as Cr increase $>50 \%$ within 7 days) were used $[4,35,36]$. Despite numerous studies, the optimal time-point for NGAL determination following coronary angiography has not yet been well elucidated [24].

Another biomarker under our examination was L-FABP. Despite the fact that our study failed to find any significant correlation between the occurrence of CI-AKI and levels of this marker, a few other studies have suggested that L-FABP level increases between 4 and $24 \mathrm{~h}$ post-contrast in CI-AKI cases [22, 32, 34]. According to Connolly et al. [22], the most predictive time point for the determination of L-FABP was at $4 \mathrm{~h}(>12.1 \mathrm{ng} / \mathrm{mL})$ when it exhibited best sensitivity of $42.3 \%$ and specificity of $90.2 \%, p=0.001$, AUC 0.69. Their study suggests that serum L-FABP may be used alone or in the combination with plasma NGAL as a pre-procedural screening tool. Other suggested markers of AKI, such as IL-18 and KIM-1 have not been studied in detail in serum, however, the available data concerning urinary levels suggests that their increase is seen after 24-48 $\mathrm{h}$ following contrast [22, 37-39]. Studies performed on animal models confirmed that caspase-1-mediated production of IL-18 played a harmful role in AKI [40]. A nested case-control study, which was performed within the Acute Respiratory Distress Syndrome (ARDS) Network trial, found that urine IL-18 values $24 \mathrm{~h}$ before the development of AKI enabled the prediction of AKI development after the adjustment for baseline and clinical characteristics. In that study, urine IL-18 value $>100 \mathrm{pg} / \mathrm{mL}$ was associated with a 6.5 -fold increased odds for developing AKI within the next $24 \mathrm{~h}(p=0.0009)$. Moreover, the area under the ROC curve for the urine IL-18 level within the next $24 \mathrm{~h}$ was $73 \%$ and before $48 \mathrm{~h}$ was $65 \%$, which implies its good performance for the early diagnosis of AKI [40, 41]. According to authors, immediate increase in serum IL-18 after cardiopulmonary bypass (CPB) was ascribed to the destruction of macrophages by the procedure, while the elevated levels of IL-18 after two hours was associated with systemic inflammation resulting from CPB [42, 43]. Moreover, they suggested that significantly higher serum IL-18 levels in AKI were related to ischemia, hypotension, hypoperfusion and the release of cytokines [42]. Also the study of patients who after cardiac surgery developed AKI and those who did not, demonstrated significantly higher plasma KIM-1 levels in group with AKI in comparison with healthy volunteers $(p<0.001)$ and with patients who had cardiac surgery but did not develop AKI [17]. In that study, AUC-ROC of plasma KIM-1 was 0.98 for the analysis comprising patients with established AKI versus healthy volunteers.

However, Connolly et al. [22] suggested that KIM-1 and IL-18 were not useful early CI-AKI predictors. In their study, median serum KIM-1 levels were not statistically different until $48 \mathrm{~h}$ post-contrast. Median KIM-1 at that time was $0.21 \mathrm{ng} / \mathrm{mL}$ in the CI-AKI group in comparison to a median of 0.16 in the non-CI-AKI group, AUC 0.65, $p=0.019$. However, due to $48 \mathrm{~h}$ delay, KIM- 1 exhibited no benefits over creatinine. Moreover, they revealed that serum IL-18 was not statistically significant at predicting CI-AKI at any time point, AUC range 0.40-0.54, $p>0.05$ [22].

In this study, we observed statistically significant changes in NGAL levels in time. Considerable increase of serum NGAL concentration was seen within $24 \mathrm{~h}$ from contrast administration and it was followed by a marked decrease of its level. This is in agreement with the results of study performed by Shaker et al. [44], which assessed biomarkers levels in patients with normal serum creatinine undergoing coronary angiography. They observed significantly higher serum NGAL levels $4 \mathrm{~h}$ and $24 \mathrm{~h}$ after coronary interventions in comparison to the baseline value (before coronary angiography) [44]. Also Bachorzewska-Gajewska et al. [32] demonstrated considerable rise in serum NGAL after 2 and $4 \mathrm{~h}$, which persisted up to $48 \mathrm{~h}$ after PCI. 
In this study we failed to find any correlation between the level of studied markers and the decrease in eGFR or the increase in creatinine level after $24 \mathrm{~h}$ and $72 \mathrm{~h}$. We noticed relationship between the level of KIM-1 and the increase in creatinine level, however, it failed to reach the significance. In turn, in the study performed by Sabbisetti et al. [17], plasma KIM-1 level was found to correlate with plasma creatinine $(r=0.58 ; p<0.001)$. Malyszko et al. [45] indicated that eGFR (beta - 0.61) in multiple regression analysis was the best predictor of urinary KIM-1, and that it explained $61 \%$ of KIM-1 concentrations in renal allograft recipients. Also Tian et al. [46] found a negative correlation between plasma KIM-1 levels and the estimated glomerular filtration rate in all participants (with AKI and with CKD) $(r=-0.725, p<0.01)$, which disappeared in subset analysis of AKI and CKD patients separately. In contrast to the results of our study, Dent et al. revealed that 2-h postoperative plasma NGAL levels strongly correlated with change in creatinine [47]. The discrepancies may be associated with the fact that we did not measure NGAL levels after $2 \mathrm{~h}$ from the procedure.

Some limitations need to be addressed. This is a small single-center study. Moreover, confounding variable such as the volume of fluid administrated before angiography was not routinely registered, therefore the analysis of its impact was not possible.

\section{Conclusions}

Multiple serum biomarkers (NGAL, KIM-1, cystatin C, IL-18, and L-FABP) have been suggested to enable early detection of AKI before the rise in serum creatinine. Serum creatinine is still the key determinant of kidney function, however, for many reasons it is not a perfect marker. Unfortunately, our study failed to demonstrate statistically significant correlations between serum levels of selected biomarkers and the occurrence of CI-AKI. The observed trend is not sufficient for the determination of efficient AKI biomarkers. The selection of optimal biomarkers still require prospective validation in large numbers of patients with AKI and in different clinical settings. Lack of statistical significance may be associated with a small number of patients.

Acknowledgements Special thanks for Marek Nocuń, who performed all statistic calculations.

Open Access This article is licensed under a Creative Commons Attribution 4.0 International License, which permits use, sharing, adaptation, distribution and reproduction in any medium or format, as long as you give appropriate credit to the original author(s) and the source, provide a link to the Creative Commons licence, and indicate if changes were made. The images or other third party material in this article are included in the article's Creative Commons licence, unless indicated otherwise in a credit line to the material. If material is not included in the article's Creative Commons licence and your intended use is not permitted by statutory regulation or exceeds the permitted use, you will need to obtain permission directly from the copyright holder. To view a copy of this licence, visit http://creativecommons.org/licenses/by/4.0/.

\section{References}

1. Makris K, Spanou L (2016) Acute kidney injury: definition, pathophysiology and clinical phenotypes. Clin Biochem Rev 37(2):85-98

2. Kumar S, Nair RK, Aggarwal N, Abbot AK, Muthukrishnan J, Kumar KH (2017) Risk factors for contrast-induced nephropathy after coronary angiography. Saudi J Kidney Dis Transpl 28:318-324

3. Firu SG, Streba CT, Firu D, Tache DE, Rogoveanu I (2015) Neutrophil Gelatinase Associated Lipocalin (NGAL) - a biomarker of renal dysfunction in patients with liver cirrhosis: do we have enough proof? J Med Life 8:15-20 (Spec Issue)

4. Rizvi MS, Kashani KB (2017) Biomarkers for early detection of acute kidney injury. J Appl Lab Med 2(3):386-399. https:// doi.org/10.1373/jalm.2017.023325

5. Fuhrman DY, Kane-Gill S, Goldstein SL, Priyanka P, Kellum JA (2018) Acute kidney injury epidemiology, risk factors, and outcomes in critically ill patients $16-25$ years of age treated in an adult intensive care unit. Ann Intensive Care 8(1):26. https ://doi.org/10.1186/s13613-018-0373-y

6. Mohammed NM, Mahfouz A, Achkar K, Rafie IM, Hajar R (2013) Contrast-induced nephropathy. Heart Views 14(3):106116. https://doi.org/10.4103/1995-705X.125926

7. Hiremath S, Vijayan A, Dave N, Raghavan R (2018) Contrast is Nephrotoxic vs Contrast is NOT Nephrotoxic.\#NephMadness: Contrast Region; https://ajkdblog.org/2018/03/15/nephmadnes s-2018-contrast-region/

8. Newhouse JH, Kho D, Rao QA, Starren J (2008) Frequency of serum creatinine changes in the absence of iodinated contrast material: implications for studies of contrast nephrotoxicity. AJR Am J Roentgenol 191(2):376-382. https://doi.org/10.2214/ AJR.07.3280

9. Ali A, Bhan C, Malik M et al (2018) The prevention and management of contrast-induced acute kidney injury: a mini-review of the literature. Cureus 10(9):e3284. https://doi.org/10.7759/ cureus. 3284

10. Kellum J, Lameire N, Aspelin P, Barsoum RS, Burdmann EA, Goldstein SL, Herzog CA, Joannidis M, Kribben A, Levey AS, MacLeod AM, Mehta RL, Murray PT, Naicker S, Opal SM, Schaefer F, Schetz M, Uchino S (2012) Kidney disease: Improving global outcomes (KDIGO) acute kidney injury work group. KDIGO clinical practice guideline for acute kidney injury. Kidney international supplements 2(1):1-138. https:// doi.org/10.1038/kisup.2012.1

11. Devarajan P (2011) Biomarkers for the early detection of acute kidney injury. Curr Opin Pediatr 23(2):194-200. https://doi. org/10.1097/MOP.0b013e328343f4dd

12. Bauvois B, Susin SA (2018) Revisiting neutrophil gelatinaseassociated lipocalin (NGAL) in cancer: saint or sinner? Cancers (Basel) 10(9):336. https://doi.org/10.3390/cancers 10090336

13. Tsigou E, Psallida V, Demponeras C, Boutzouka E, Baltopoulos G (2013) Role of new biomarkers: functional and structural damage. Crit Care Res Pract 2013:361078. https://doi. org/10.1155/2013/361078

14. Andreucci M, Faga T, Riccio E, Sabbatini M, Pisani A, Michael A (2016) The potential use of biomarkers in predicting 
contrast-induced acute kidney injury. Int J Nephrol Renovasc Dis 9:205-221. https://doi.org/10.2147/IJNRD.S105124

15. Quintavalle C, Anselmi CV, De Micco F, Roscigno G, Visconti G, Golia B et al (2015) Neutrophil gelatinase-associated lipocalin and contrast-induced acute kidney injury. Circ Cardiovase Interv 8:1-11

16. Han WK, Bailly V, Abichandani R, Thadhani R, Bonventre JV (2002) Kidney Injury Molecule-1 (KIM-1): a novel biomarker for human renal proximal tubule injury. Kidney Int 62(1):237-244

17. Sabbisetti VS, Waikar SS, Antoine DJ, Smiles A, Wang C, Ravisankar A, Ito K, Sharma S, Ramadesikan S, Lee M, Briskin R, De Jager PL, Ngo TT, Radlinski M, Dear JW, Park KB, Betensky R, Krolewski AS, Bonventre JV (2014) Blood kidney injury molecule-1 is a biomarker of acute and chronic kidney injury and predicts progression to ESRD in type I diabetes. J Am Soc Nephrol 25(10):2177-2186. https://doi.org/10.1681/ASN.2013070758

18. Wu H, Craft ML, Wang P, Wyburn KR, Chen G, Ma J, Hambly B, Chadban SJ (2008) IL-18 contributes to renal damage after ischemia-reperfusion. J Am Soc Nephrol 19(12):2331-2341. https ://doi.org/10.1681/ASN.2008020170

19. Kamijo-Ikemori A, Ichikawa D, Matsui K, Yokoyama T, Sugaya T, Kimura K (2013) Urinary L-type fatty acid binding protein (L-FABP) as a new urinary biomarker promulgated by the Ministry of Health, Labour and Welfare in Japan. Rinsho Byori 61(7):635-640 (Article in Japanese)

20. Malyszko J, Bachorzewska-Gajewska H, Poniatowski B, Malyszko JS, Dobrzycki S (2009) Urinary and serum biomarkers after cardiac catheterization in diabetic patients with stable angina and without severe chronic kidney disease. Ren Fail 10:910-919. https ://doi.org/10.3109/08860220903216113

21. Levey AS, Bosch JP, Lewis JB et al (1999) A more accurate method to estimate glomerular filtration rate from serum creatinine: a new prediction equation. Modification of Diet in Renal Disease Study Group. Ann Intern Med 130:461-470

22. Connolly M, Kinnin M, McEneaney D, Menown I, Kurth M, Lamont J, Morgan N, Harbinson M (2018) Prediction of contrast induced acute kidney injury using novel biomarkers following contrast coronary angiography. QJM Int J Med 111(2):103-110. https://doi.org/10.1093/qjmed/hcx201

23. Ponikowski P, Voors AA, Anker SD, Bueno H, Cleland JGF, Coats AJS, Falk V, González-Juanatey JR, Harjola VP, Jankowska EA, Jessup M, Linde C, Nihoyannopoulos P, Parissis JT, Pieske B, Riley JP, Rosano GMC, Ruilope LM, Ruschitzka F, Rutten FH, van der Meer P (2016) ESC scientific document group, 2016 ESC guidelines for the diagnosis and treatment of acute and chronic heart failure: the task force for the diagnosis and treatment of acute and chronic heart failure of the European Society of Cardiology (ESC). Acute and chronic heart failure guidelines ESC clinical practice guidelines. EHJ (2016) 37(27):2129-2200. https ://doi.org/10.1093/eurheartj/ehw128

24. Valero E, Rodríguez JC, Moyano P, Miñana G, Sanchis J, Núñez J (2016) Role of neutrophil gelatinase-associated lipocalin in the detection of contrast-induced nephropathy in patients undergoing a coronary angiography. Revista Española de Cardiología 69(5):524-525

25. Miñana NG, Santas E, Bertomeu-González V (2015) Cardiorenal syndrome in acute heart failure: revisiting paradigms. Rev Esp Cardiol 68:426-435. https://doi.org/10.1016/j.rec.2014.10.016

26. Charlton JR, Portilla D, Okusa MD (2014) A basic science view of acute kidney injury biomarkers. Nephrol Dial Transplant 29(7):1301-1311

27. Mishra J, Dent C, Tarabishi R, Mitsnefes MM, Ma Q, Kelly C, Ruff SM, Zahedi K, Shao M, Bean J, Mori K, Barasch J, Devarajan P (2005) Neutrophil gelatinase-associated lipocalin (NGAL) as a biomarker for acute renal injury after cardiac surgery. Lancet 365(9466):1231-1238

28. Ronco C (2014) Biomarkers for acute kidney injury: is NGAL ready for clinical use? Crit Care 18(6):680

29. Haase M, Devajaran P, Haase-Fielitz A, Bellomo R, Cruz DN, Wagener $\mathrm{G}$ et al (2011) The outcome of neutrophil gelatinaseassociated lipocalin-positive subclinical acute kidney injury: a multicenter pooled analysis of prospective studies. J Am Coll Cardiol 57:1752-1761. https://doi.org/10.1016/j.jacc.2010.11.051

30. Connolly M, McEneaney D, Menown I, Morgan N, Harbinson M (2015) Novel biomarkers of acute kidney injury after contrast coronary angiography. Cardiol Rev 23:240-246

31. Padhy M, Kaushik S, Girish MP, Mohapatra S, Shah S, Koner BC (2014) Serum neutrophil gelatinase associated lipocalin (NGAL) and cystatin $\mathrm{C}$ as early predictors of contrast-induced acute kidney injury in patients undergoing percutaneous coronary intervention. Clin Chim Acta 435:48-52. https://doi.org/10.1016/j. cca.2014.04.016

32. Bachorzewska-Gajewska H, Poniatowski B, Dobrzycki S (2009) NGAL (neutrophil gelatinase-associated lipocalin) and L-FABP after percutaneous coronary interventions due to unstable angina in patients with normal serum creatinine. Adv Med Sci 54:221-224

33. Bachorzewska-Gajewska H, Malyszko J, Sitniewska E, Malyszko S, Pawlak K, Mysliwiec M (2007) Could neutrophil gelatinaseassociated lipocalin and cystatin $\mathrm{C}$ predict the development of contrast induced acute kidney injury after percutaneous coronary intervention in patients with stable angina and normal serum creatinine levels? Kidney Press Res 30:408-415

34. Ling W, Zhaohui N, Ben H, Leyi G, Jianping L, Huili D et al (2008) Urinary IL-18 and NGAL as early predictive biomarkers in contrast-induced nephropathy after coronary angiography. Nephron Clin Pract 108:176-181

35. Haase M, Bellomo R, Haase-Fielitz A (2010) Neutrophil gelatinase-associated lipocalin. Curr Opin Crit Care 16:526-532

36. Michael H, Rinaldo B, Prasad D, Peter S, Anja H-F (2009) Accuracy of neutrophil gelatinase-associated lipocalin (NGAL) in diagnosis and prognosis in acute kidney injury: a systematic review and meta-analysis. Am J Kidney Dis 54:1012-1024

37. Malyszko J, Bachorzewska-Gajewska H, Poniatowski B, Malyszko JS, Dobrzycki S (2009) Urinary and serum biomarkers after cardiac catheterization in diabetic patients with stable angina and without severe chronic kidney disease. Ren Fail 31:910-919

38. Endre ZH, Pickering JW, Walker RJ, Devarajan P, Edelstein CL, Bonventre JV et al (2011) Improved performance of urinary biomarkers of acute kidney injury in the critically ill by stratification for injury duration and baseline renal function. Kidney Int 79:1119-1130

39. Nejat M, Pickering J, Walker R, Westhuyzen J, Shaw GM, Frampton $\mathrm{CM}$ et al (2010) Urinary cystatin $\mathrm{C}$ is diagnostic of acute kidney injury and sepsis, and predicts mortality in the intensive care unit. Crit Care 14:R85

40. Edelstein CL, Hoke TS, Somerset H et al (2007) Proximal tubules from caspase-1-deficient mice are protected against hypoxia-induced membrane injury. Nephrol Dial Transplant 22(4):1052-1061

41. Simsek A, Tugcu V, Tasci AI (2013) New biomarkers for the quick detection of acute kidney injury. ISRN Nephrol 2013:394582. https://doi.org/10.5402/2013/394582

42. Ünal EU, Özen A, Boysan E, Tak S, Başar V, Türkcan BS, Durukan E, Tütün U, Birincioğlu CL (2014) Serum interleukin-18 as an early marker of acute kidney injury following open heart surgery. Turk Gogus Kalp Dama 22(3):483-488

43. Rosner MH, Okusa MD (2006) Acute kidney injury associated with cardiac surgery. Clin J Am Soc Nephrol 1:19-32 
44. Shaker OG, El-Shehaby A, El-Khatib M (2010) Early diagnostic markers for contrast nephropathy in patients undergoing coronary angiography. Angiology 61(8):731-736

45. Malyszko J, Koc-Zorawska E, Malyszko JS, Mysliwiec M (2010) Kidney injury molecule-1 correlates with kidney function in renal allograft recipients. Transplant Proc 42(10):3957-3959. https:// doi.org/10.1016/j.transproceed.2010.10.005

46. Tian L, Shao X, Xie Y, Wang Q, Che X, Zhang M, Xu W, Xu Y, Ni Z, Mou S (2017) Kidney injury molecule-1 is elevated in nephropathy and mediates macrophage activation via the mapk signalling pathway. Cell Physiol Biochem 41:769-783
47. Dent C, Dastrala S, Bennet M et al (2007) Plasma NGAL predicts AKI, morbidity and mortality after pediatric cardiac surgery: A prospective uncontrolled cohort study. Crit Care 11:R127-R132

Publisher's Note Springer Nature remains neutral with regard to jurisdictional claims in published maps and institutional affiliations. 